Article

\title{
Analysis of Diesel Knock for High-Altitude Heavy-Duty Engines Using Optical Rapid Compression Machines
}

\author{
Xiangting Wang ${ }^{1}$, Haiqiao Wei ${ }^{1}$, Jiaying Pan ${ }^{1} * \mathbb{C}^{\mathbb{D}}$, Zhen $\mathrm{Hu}^{1}$, Zeyuan Zheng ${ }^{2}$ \\ and Mingzhang Pan ${ }^{2}$ \\ 1 State Key Laboratory of Engines, Tianjin University, Tianjin 300072, China; wxt19960822@tju.edu.cn (X.W.); \\ whq@tju.edu.cn (H.W.); huzhen@tju.edu.cn (Z.H.) \\ 2 School of Mechanical Engineering, Guangxi University, Nanning 530004, China; \\ 1811302016@st.gxu.edu.cn (Z.Z.); pmz@gxu.edu.cn (M.P.) \\ * Correspondence: jypan@tju.edu.cn
}

Received: 23 May 2020; Accepted: 12 June 2020; Published: 14 June 2020

check for updates

\begin{abstract}
In high altitude regions, affected by the low-pressure and low-temperature atmosphere, diesel knock is likely to be encountered in heavy-duty engines operating at low-speed and high-load conditions. Pressure oscillations during diesel knock are commonly captured by pressure transducers, while there is a lack of direct evidence and visualization images, such that its fundamental formation mechanism is still unclear. In this study, optical experiments on diesel knock with destructive pressure oscillations were investigated in an optical rapid compression machine. High-speed direct photography and simultaneous pressure acquisition were synchronically performed, and different injection pressures and ambient pressures were considered. The results show that for the given ambient temperature and pressure, diesel knock becomes prevalent at higher injection pressures where fuel spray impingement becomes enhanced. Higher ambient pressure can reduce the tendency to diesel knock under critical conditions. For the given injection pressure satisfying knocking combustion, knock intensity is decreased as ambient pressure is increased. Further analysis of visualization images shows diesel knock is closely associated with the prolonged ignition delay time due to diesel spray impingement. High-frequency pressure oscillation is caused by the propagation of supersonic reaction-front originating from the second-stage autoignition of mixture. In addition, the oscillation frequencies are obtained through the fast Fourier transform (FFT) analysis.
\end{abstract}

Keywords: diesel knock; rapid compression machine; spray impingement; auto-ignition; reaction front propagation

\section{Introduction}

According to mega data statistics, more than six million automobiles are operated in high altitude regions around the world [1]. The atmospheric temperatures and pressures are relatively low at high altitude regions. Consequently, with the increase of altitude, ignition delay time is longer and burning rates become slower, resulting in an enhanced pressure rise rate in the premixed combustion stage [2,3]. Consequently, severe diesel knock with destructive pressure oscillation is likely to occur in heavy-duty diesel engines under low-speed and high-load conditions. When diesel knock occurs at high altitude regions, the amplitude of pressure oscillation can reach several dozens of atmosphere, which results in cylinder head erosion and piston crown breakdown [4]. However, the detailed mechanism for such an abnormal combustion still remains unclear.

Generally, diesel knock is characterized by excessive noise and vibration due to the over-quick pressure rise rate [5]. Several studies have been performed to quantify the characteristics of pressure 
oscillations through pressure measurements [6-8]. Compared with the common pressure measurements, optical diagnostics are extensively employed nowadays as effective tools to identify the underlying mechanism(s) for engine knock, Rusly et al. [9] performed high-speed imaging of soot luminosity combining with in-cylinder pressure measurement in an optical diesel engine, and they found that flames were observed to oscillate seriously when diesel knock occurred. Zhao et al. [10] conducted abnormal combustion experiments in an optical diesel engine, and they observed that diesel knock involved end-gas autoignition, fast subsonic flame propagation, and strong pressure waves (and even shock waves). However, most of the previous optical studies have addressed the scenarios of spark-ignition (SI) engines [11-14], while there is a lack of optical investigations addressing diesel knock. Optical visualizations or fundamental researches are still lack due to the destructive effect of diesel knock, which limits the clarification of diesel knock formation, especially for heavy-duty engines operating at high altitude regions.

Currently, high injection pressures are applied in high altitude diesel engines to pursue superior power efficiency and fuel economy [15]. However, the low ambient intake conditions and the increasing injection pressure will prolong spray penetration, which leads to a large possibility of spray impingement $[16,17]$. Spray impingement is considered as a potential cause of diesel knock because attached film combustion and strong pressure oscillations are measured in realistic heavy-duty diesel engines [18]. Du et al. [19] experimentally investigated the effects of fuel injection pressure (FIP) on combustion characteristics under spray impingement conditions in a constant-volume combustion chamber, and the results showed that impinging spray prolonged ignition delay time at high injection pressures. Amir Khalid and co-workers [20,21] carried out optical experiments within a wide range of ambient conditions and fuel injection pressures. The results showed that the FIP and ambient pressures showed significant influences on the fuel evaporation and fuel-air premixing before ignition. Jain et al. [22] investigated the effects of FIP on combustion characteristics in a partially premixed charge compression ignition (PCCI) engine, and they found that that appropriate FIPs promoted combustion due to improved spray atomization. However, further increasing FIP resulted in diesel knock. In conventional diesel engines, longer ignition delay time tends to lead to pressure oscillations owing to the rapid localized pressure rise rates in the premixed combustion stage [23]. However, fundamental investigations on the role of the FIP and the altitude in diesel knock remain scarce when spray impingement is encountered.

With the above considerations, the primary objectives of this study are to explore the combustion characteristics and the underlying reasons for high altitude heavy-duty engines. Optical experiments were reproduced in an optical RCM with well-controlled boundary conditions. The RCM setup can bear extreme conditions and simulate similar conditions of realistic engines. High-speed direct photography and simultaneous pressure acquisition were synchronically performed, and the role of injection pressure and ambient pressure conditions in diesel knock were considered. Visualized images were conducted to understand spray impingement, localized autoignition initiation, and reaction front propagation. The current observations from fundamental experiments can provide useful insights into knock mechanism and its regulations of heavy diesel engines at high altitude conditions.

\section{Experimental Setup and Methodology}

\subsection{Experimental Setup}

The current studies were conducted in a newly designed high-strength optical RCM in the State Key Laboratory of Engines (SKLE) at Tianjin University. The schematic of the RCM setup is presented in Figure 1. The RCM setup consisted of five major sub-systems, including a compression chamber, a combustion chamber, a pneumatically driven chamber, a hydraulically damped chamber, and a high-pressure air tank. The RCM beared a maximum pressure as high as $30 \mathrm{MPa}$ and reached a target pressure as much as $6 \mathrm{MPa}$ at the top dead center (TDC). By adjusting the compression stroke and clearance volume, the compression ratio could vary from 10 to 21 to achieve different ambient 
conditions encountered in realistic diesel engines. Meanwhile, a flat piston with crevice containment concept was deigned to guarantee the homogenous environment and avoid roll-up vortices [24]. A high-accuracy motional pickup transducer was equipped to measure the law of piston motion.

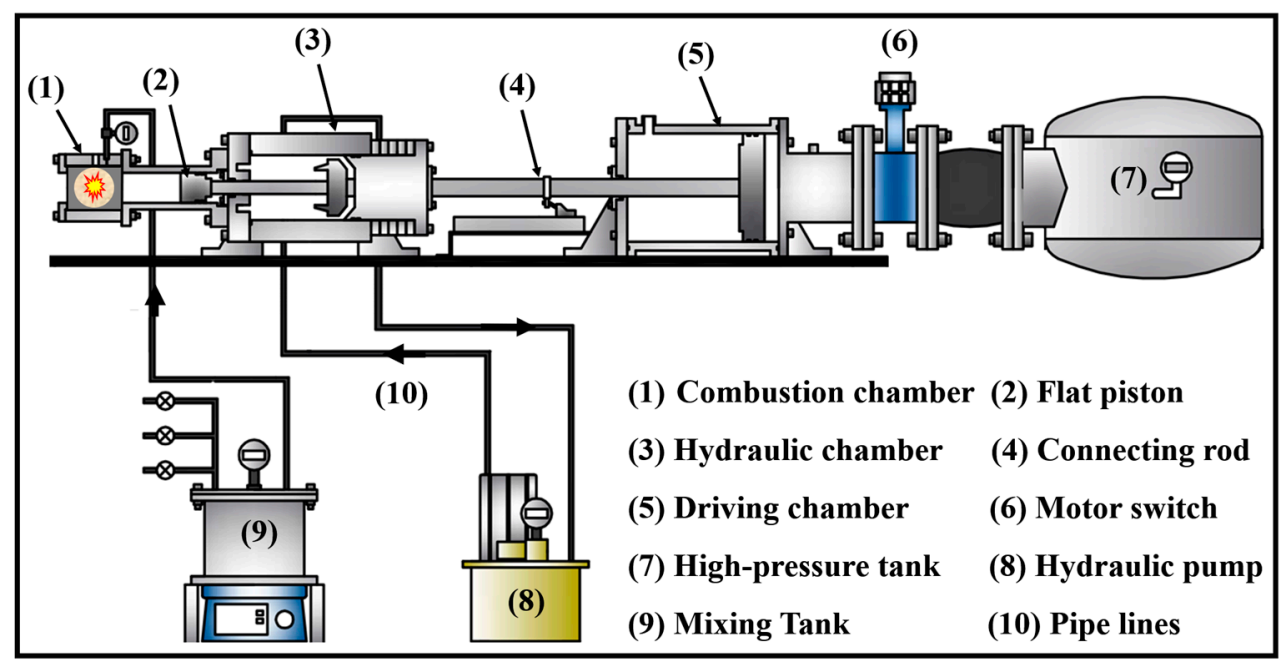

Figure 1. Schematic of high-strength optical rapid compression machine setup.

To understand the pressure characteristics of diesel knock, the dynamic pressure trajectories were measured by a piezoelectric pressure transducer (Kistler 6045A, Winterthur, Switzerland). Then the voltage signal was amplified by a charge amplifier (Kistler 5064C, Winterthur, Switzerland), and then was collected by data acquisition equipment (USB 6366, National Instruments, Shenzhen, China) at a frequency of $100 \mathrm{kHz}$ and finally saved to the computer. To visualize the combustion evolution, the combustion chamber was equipped with a high-pressure resistance quartz glasses with a thickness of $40 \mathrm{~mm}$ in the axial direction. A high-speed direct camera (SA-Z, Photron, Tokyo, Japan) with a $105 \mathrm{~mm}$ lens (Nikkor 1: 2.8 D, AFMicro, Tokyo, Japan) was used to record the combustion images. The camera frame rate reached a frequency of up to $200,000 \mathrm{~Hz}$ ( $5 \mu \mathrm{s} /$ frame) at the resolution of $320 \times 128$ pixels. The shutter speed was set to $8.39 \mu$ s and the lens aperture was maximized to improve definition and underexposure during combustion. At the same time, the camera was synchronously triggered by transient pressure signals with a defined threshold. In addition, a commercial fuel injector with a single hole was edge-installed in the combustion chamber. Figure 2 shows a schematic of the optical combustion chamber with a pressure transducer and a fuel injector.
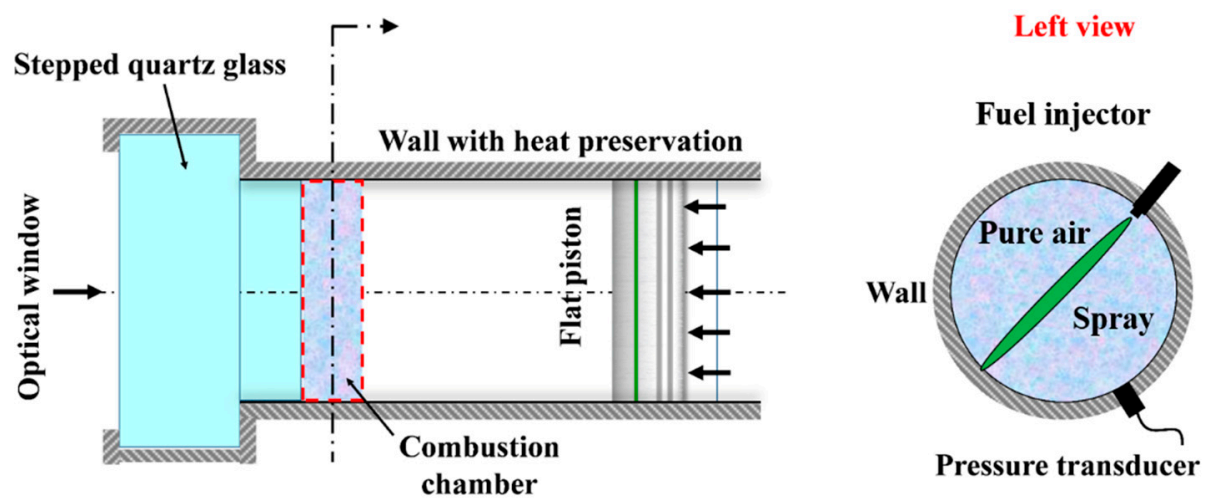

Figure 2. Schematic of optical combustion chamber and fuel injector and pressure transducer layout.

In the experiments, a single-shot common-rail fuel injection system (Bosch, Stuttgart, Germany) was employed, which provided a maximum injection pressure up to $140 \mathrm{MPa}$. The diameter (d) of the single hole injector maintained at $0.32 \mathrm{~mm}$ to simulate the actual scenarios of heavy-duty diesel 
engines. The test fuel is straight diesel fuel with a cetane number of 42.3. More detailed properties are provided in Table 1. According to the SH/T0606-2005 method [25], the composition of diesel fuel was analyzed to understand the autoignition characteristics. To accurately control a solenoid force, the injector is controlled by an injector driver box and a LabView VI (National Instruments). Meanwhile, a Transistor-Transistor-Logic (TTL) pulse is employed to control injection timing and pulse width to quantify the injected mass in the experiment. Figure 3 shows the calibration of injection mass versus fuel injection pressure. Besides, the injector body is water-cooled to ensure the injector operates normally when the RCM is heated.

Table 1. Fuel properties of the diesel fuel in the experiment.

\begin{tabular}{cc}
\hline Diesel Fuel & Straight-Run Diesel \\
\hline Viscosity $\left(\mathrm{mm}^{2} / \mathrm{s}\right)$ at $293 \mathrm{~K}$ & 2.344 \\
Cetane number & 42.3 \\
Density $\left(\mathrm{kg} / \mathrm{m}^{3}\right)$ at $293 \mathrm{~K}$ & 817.0 \\
Flash point $(\mathrm{K})$ & 335.0 \\
Low heating value $(\mathrm{MJ} / \mathrm{kg})$ & 42.84 \\
Distillation of $50 \%(\mathrm{~K})$ & 518.5 \\
Distillation of $90 \%(\mathrm{~K})$ & 601.4 \\
\hline
\end{tabular}

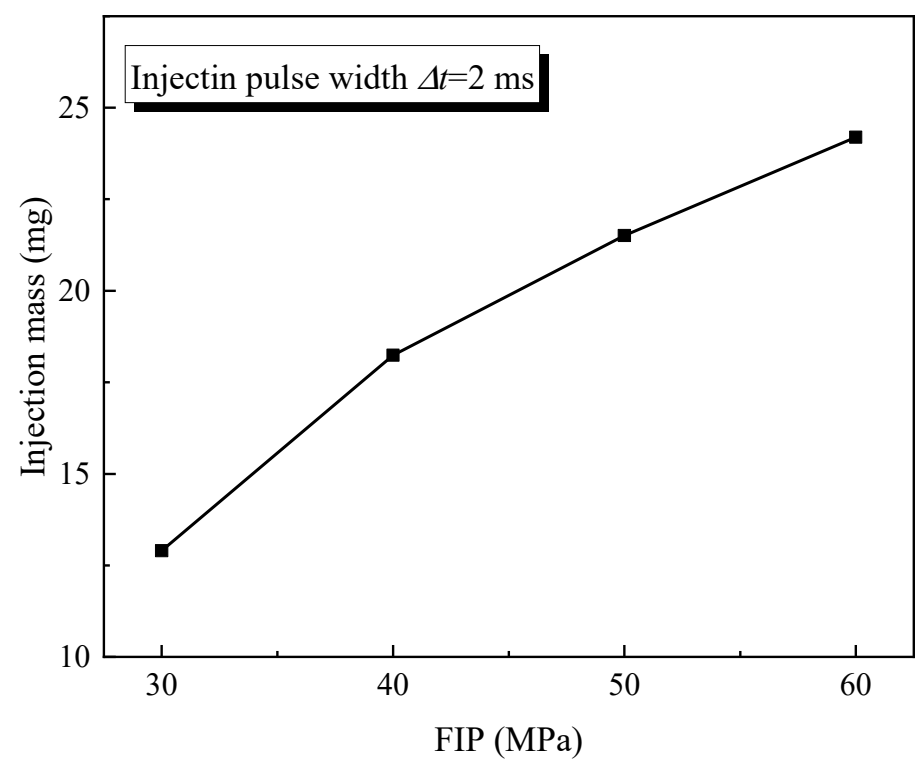

Figure 3. Calibration results of injection mass versus fuel injection pressure.

\subsection{Test Operation Conditions}

In the experiments, ultra-high purity air (>99.999\%) consisting of $21 \% \mathrm{O}_{2}$ and $79 \% \mathrm{~N}_{2}$ was firstly prepared in a 6.01 mixing tank to adopt as background gases. The amounts of pure air and fuel mass was calculated at ambient conditions. Meanwhile, the mixing tank was equipped with a magnetic stirring apparatus and it was taken at least $2 \mathrm{~h}$ to improve the mixture homogeneity. An electric heating system involving PID control was used to heat all connection pipelines, and the target temperature was the same as the mixture inside the mixing tank to avoid fuel condensation. To mimic the realistic wall temperature in diesel engines, the wall temperature of RCM chamber $\left(T_{w}\right)$ was maintained at $353 \mathrm{~K}$ [9].

Table 2 shows the experimental conditions of the current study. The fuel injection pressure was varied from $30 \mathrm{MPa}$ to $60 \mathrm{MPa}$ to investigate the influence of FIP. The start of injection (SOI) timing was triggered when the instantaneous in-cylinder pressure $\left(P_{S O I}\right)$ reached $1.0 \mathrm{MPa}$ to simulate the engine scenarios under high altitude conditions. However, there is a slight difference in injection timing because fuel injector needs certain response time for the signals from microcontrollers. Two groups of 
injection pulse widths $(\Delta t)$ were adopted (i.e. $\Delta t=1.5 \mathrm{~ms}$ and $\Delta t=2.0 \mathrm{~ms}$ ) to consider the effect of injection mass on diesel knock. The respected target pressures at the TDC $\left(P_{c}\right)$ were $P_{c} \approx 2.0 \mathrm{MPa}$ and $P_{c} \approx 4.0 \mathrm{MPa}$ through adjusting intake pressure $\left(P_{i}\right)$, comparable to the realistic engine scenarios at high altitude regions (e.g. $4000 \mathrm{~m}$ and $1500 \mathrm{~m}$ ) [26]. The intake temperature $\left(T_{i}\right)$ was controlled at $343 \mathrm{~K}$, and the target temperature at the TDC $\left(T_{\mathcal{c}}\right)$ was calculated by an adiabatic core hypothesis relation [27]:

$$
\int_{T_{i}}^{T_{c}} \frac{\gamma}{\gamma-1} \frac{d T}{T}=\ln \left(\frac{P_{c}}{P_{i}}\right)
$$

where $\gamma$ is the specific heat ratio. It is noted that the specific heat ratio of different temperatures has been obtained based on a table checking method. Each experimental test was repeated at least three times at each operating point to improve the consistency of experimental results. Because spray impingement may result in soot production and deposition, the RCM chamber has to be cleaned after each operating condition to avoid the concerns accumulation of soot particles.

Table 2. Test conditions for RCM experiments.

\begin{tabular}{cccccccc}
\hline $\mathbf{D}(\mathbf{m m})$ & $\boldsymbol{P}_{\boldsymbol{i}}(\mathbf{M P a})$ & $\boldsymbol{T}_{\boldsymbol{i}}(\mathbf{K})$ & $\boldsymbol{P}_{\boldsymbol{c}}(\mathbf{M P a})$ & $\boldsymbol{T}_{\boldsymbol{c}}(\mathbf{K})$ & $\boldsymbol{P}_{\boldsymbol{S O I}}(\mathbf{M P a})$ & $\mathbf{F I P}(\mathbf{M P a})$ & $\boldsymbol{\Delta} \boldsymbol{t}(\mathbf{m s})$ \\
\hline 70 & 0.065 & 343 & 2.14 & $930.8 \pm 5$ & 1.0 & $30-60$ & $1.5,2.0$ \\
70 & 0.130 & 343 & 4.13 & $921.4 \pm 5$ & 1.0 & $30-60$ & $1.5,2.0$ \\
\hline
\end{tabular}

Figures 4 and 5 show the operational stabilities of non-reactive and knocking conditions. It can be observed that for non-reactive cycles, the pressure trace at different tests shares almost the same trajectories during the whole process. Meanwhile, the pressure varies within $0.03 \mathrm{MPa}$ at the TDC. For diesel knock scenarios, there are still some differences in autoignition onset and the peak of pressure trajectories under abnormal conditions due to the stochastic nature caused by in-cylinder temperature inhomogeneities. However, the pressure varies within $0.04 \mathrm{MPa}$ at the TDC while the corresponding injection timing is around $0.04 \mathrm{~ms}$. In spite of this, the current RCM setup still shows good repeatability in diesel knock. Besides, it is worth noting that diesel knock intensity $\left(\Delta P_{\max }\right)$ is defined as the maximum amplitude of pressure oscillation obtained from in-cylinder transient pressure using 4-25 kHz bandpass filtering with a fast Fourier transformation. Based on previous knocking studies in SI engines [28], the combustion cycles with $\Delta P_{\max }>2.0 \mathrm{MPa}$ can be regarded as super-knock events. Herein, a similar method is also employed to distinguish the different modes of diesel knock.

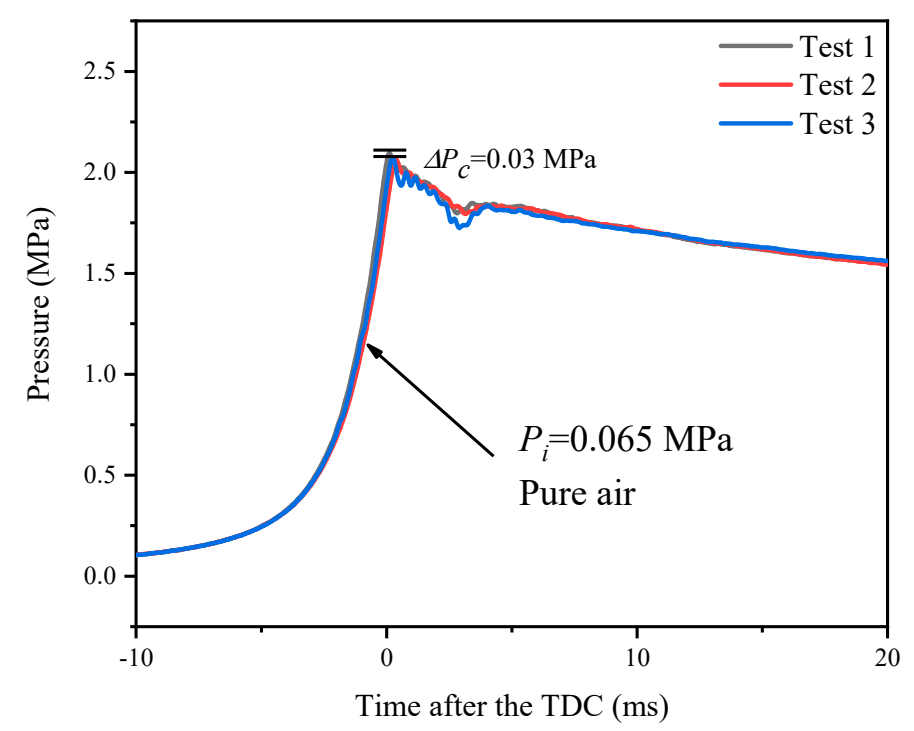

Figure 4. The stability of RCM experiments for pure air compression. 


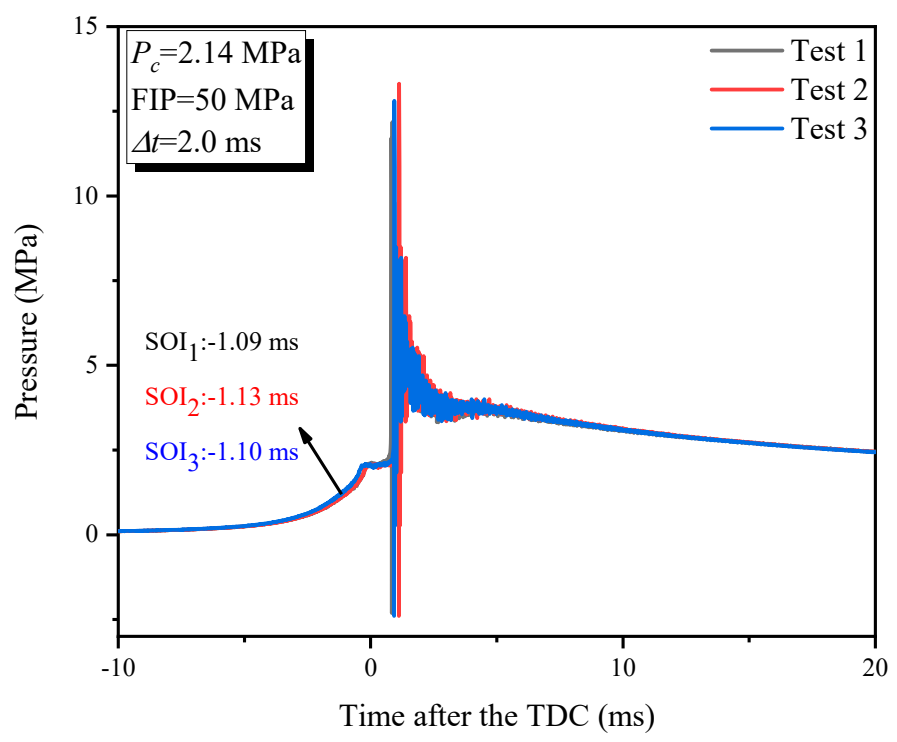

Figure 5. The capability of RCMs in studying diesel knock.

\section{Results and Discussion}

\subsection{Effects of Fuel Injection Pressure}

The effects of fuel injection pressure on diesel knock are firstly investigated at two different compression pressures. As can be seen from Figure 6, the pressure and pressure oscillation curves show different characteristics with the variation of fuel injection pressure. Specifically, there is no obvious pressure rise at FIP $=30 \mathrm{MPa}$, until FIP is increased to $40 \mathrm{MPa}$ where harness combustion is encountered under the conditions of $P_{c}=2.14 \mathrm{MPa}$. However, the maximum pressure is only $6.44 \mathrm{MPa}$. It should be noted for the conditions of $P_{c}=2.14 \mathrm{MPa}$ and FIP $=40 \mathrm{MPa}$, normal combustion with slight pressure oscillation is observed. As fuel injection pressure is elevated to $50 \mathrm{MPa}$, in-cylinder pressure rises rapidly and abnormal combustion begins to happen. Further increasing FIP up to $60 \mathrm{MPa}$, knock intensity is enhanced under the both two scenarios. The peak of pressure oscillations reach $\Delta P_{\max }=7.98 \mathrm{MPa}\left(P_{c}=2.14 \mathrm{MPa}\right)$ and $\Delta P_{\max }=5.85 \mathrm{MPa}\left(P_{c}=4.13 \mathrm{MPa}\right)$, which are manifested super-knock level according to knock criteria aforementioned [4]. Therefore, for the given compressed pressure, diesel knock becomes prevalent with the increase of fuel injection pressure.
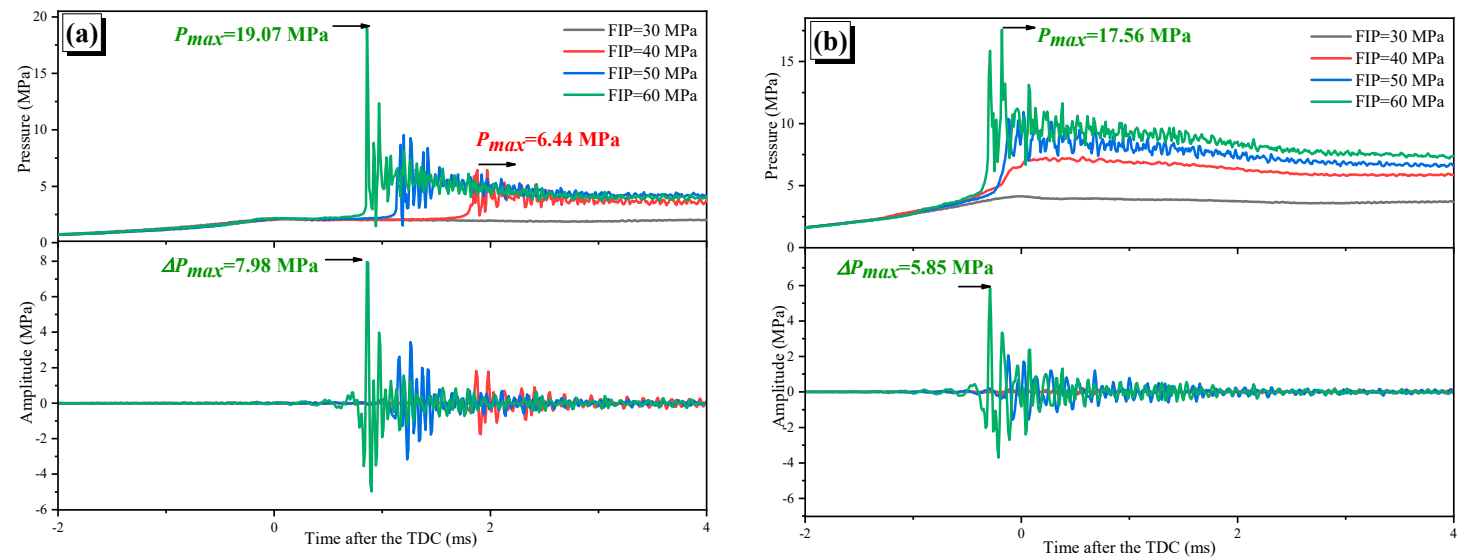

Figure 6. In-cylinder pressure and pressure oscillations at: (a) $T_{c}=930.8 \mathrm{~K}, P_{c}=2.14 \mathrm{MPa}, \Delta t=1.5 \mathrm{~ms}$; (b) $T_{c}=921.4 \mathrm{~K}, P_{c}=4.13 \mathrm{MPa}, \Delta t=1.5 \mathrm{~ms}$.

The elevated knock intensity may be attributed by the increases in diesel injection mass at higher FIP. More diesel fuel mass results in massive fuel-air mixture formation before premixed combustion, 
which enhances the energy release and enlarges the amplitude of pressure oscillation. To further illustrate the influence of diesel injection mass, Figure 7 shows the results of the injection pulse width at $\Delta t=2 \mathrm{~ms}$. It can be observed that compared with $\Delta t=1.5 \mathrm{~ms}$ scenarios, knock intensity becomes more violent with the increase of FIP from $40 \mathrm{MPa}$ to $60 \mathrm{MPa}$. To be more specific, the strongest knock intensity occurs at FIP $=60 \mathrm{MPa}$, with the peaks of pressure oscillation of $\Delta P_{\max }=9.49 \mathrm{MPa}$ at $P_{c}=2.14 \mathrm{MPa}$ and $\Delta P_{\max }=6.43 \mathrm{MPa}$ at $P_{c}=4.13 \mathrm{MPa}$, respectively.
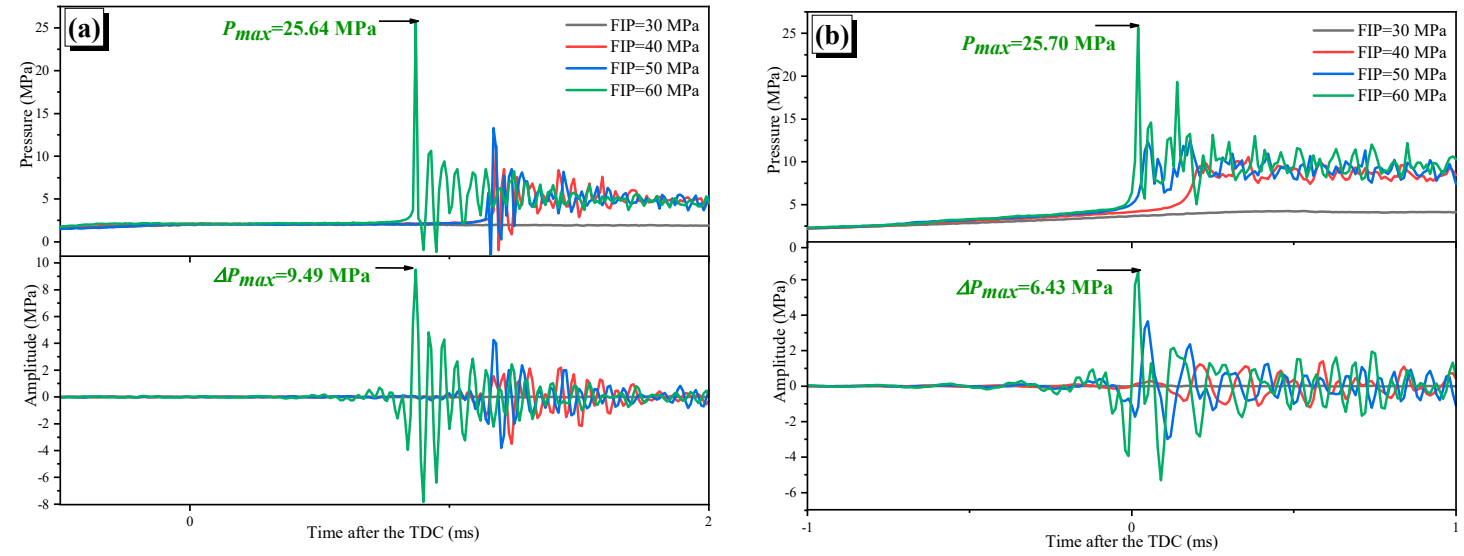

Figure 7. In-cylinder pressure and pressure oscillations for: (a) $T_{\mathcal{c}}=930.8 \mathrm{~K}, P_{\mathcal{c}}=2.14 \mathrm{MPa}, \Delta t=2.0 \mathrm{~ms}$; (b) $T_{\mathcal{c}}=921.4 \mathrm{~K}, P_{\mathcal{c}}=4.13 \mathrm{MPa}, \Delta t=2.0 \mathrm{~ms}$.

To further clarify the effects of FIP, Figure 8 provides the spray characteristics and combustion evolution at $T_{c}=930.8 \mathrm{~K}, P_{c}=2.14 \mathrm{MPa}$, and $\Delta t=1.5 \mathrm{~ms}$. It is observed that a small amount of combustible mixture starts to ignite near the injector due to the limited momentum and penetration rate at low injection pressures (i.e. FIP $=30 \mathrm{MPa}$ ). Meanwhile, it is comparatively difficult to form flame kernel and propagate forward owing to the poor atomization process. When elevating injection pressure, the liquid spray begins to impinge the chamber wall with a higher penetration rate. However, the impinging fuel cannot be ignited immediately due to the low temperature of wall surface $\left(T_{w}=353 \mathrm{~K}\right)$, which may facilitate the fuel-air mixing process [19]. As can be seen from Figure $8 \mathrm{~b}-\mathrm{d}$, an area with blue luminosity occurs at the near-wall region adjacent to the location of spray-wall impingement, and the blue luminosity represents the auto-ignition of vaporized fuel-air mixtures. The liquid spray impinges against the chamber wall in advance due to the larger momentum at higher FIPs [29], which causes the occurrence of auto-ignition earlier. Higher FIPs also provide a higher upward gas velocity [30], pushing the auto-ignition location farther from the spray-wall impingement region. Based on the radius of autoignition region, the blue reaction wave speeds can be quantified. It shows that the propagation speeds are increased significantly with varying FIP from $30 \mathrm{MPa}$ to $60 \mathrm{MPa}$, which shortens combustion duration and enhances knock intensity.

\subsection{Effects of Ambient Pressure}

In the previous section, there are obviously different pressure characteristics under different compressed pressures with FIP variations. The effects of ambient pressure are further discussed to investigate the combustion performance for a high-altitude diesel engine. As shown in Figures 7 and 8 , knock intensity is higher with increasing FIP from $30 \mathrm{MPa}$ to $60 \mathrm{MPa}$ under low ambient pressure $\left(P_{c}=2.14 \mathrm{MPa}\right)$. Meanwhile, the impacts of ambient pressure are divided into two regions, including critical conditions $(\mathrm{FIP}=40 \mathrm{MPa})$ and knocking conditions $(\mathrm{FIP}=50-60 \mathrm{MPa})$. 

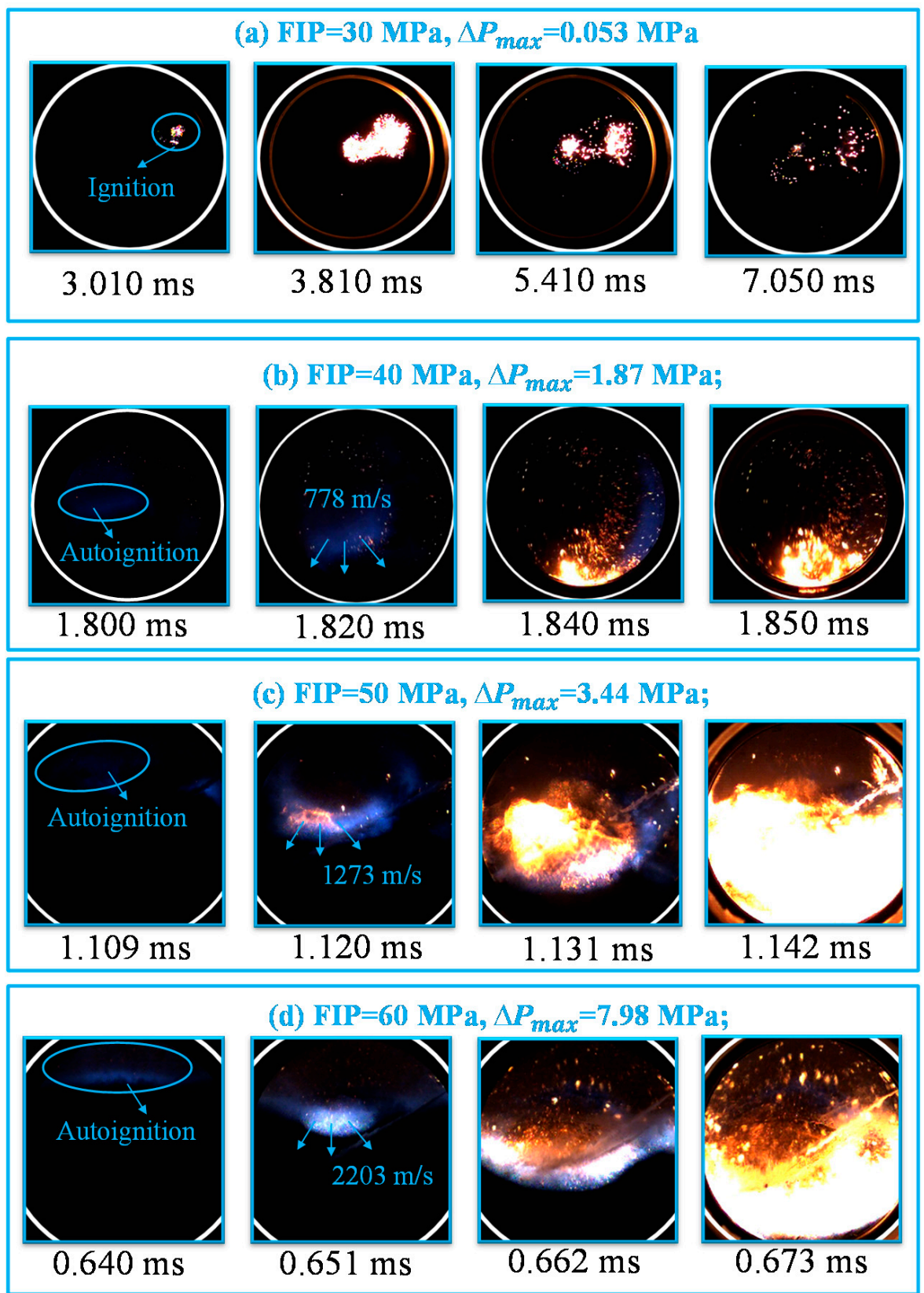

Figure 8. Selected images of combustion evolution under the conditions of $T_{c}=930.8 \mathrm{~K}, P_{c}=2.14 \mathrm{MPa}$, $\Delta t=1.5 \mathrm{~ms}:(\mathbf{a}) \mathrm{FIP}=30 \mathrm{MPa}, \Delta P_{\max }=0.053 \mathrm{MPa}$; (b) FIP $=40 \mathrm{MPa}, \Delta P_{\max }=1.87 \mathrm{MPa}$; (c) FIP $=50 \mathrm{MPa}$, $\Delta P_{\max }=3.44 \mathrm{MPa}$; (d) FIP $=60 \mathrm{MPa}, \Delta P_{\max }=7.98 \mathrm{MPa}$.

\subsubsection{Critical Conditions}

Figure 9a firstly shows in-cylinder pressure curves under the conditions of FIP $=40 \mathrm{MPa}$. The results show that diesel knock is only encountered under the conditions of $P_{c}=2.14 \mathrm{MPa}$. Although the cylinder pressure at the start of injection is set at $P_{S O I}=1.0 \mathrm{MPa}$ under two scenarios, the ambient pressure at $P_{c}=4.13 \mathrm{MPa}$ is higher during injection duration. Besides, it can be clearly seen that higher ambient pressure leads to a shorter ignition delay period and earlier rise of pressure. Generally, the evaporation process of spray droplets needs to absorb heat, resulting in a decrease of ambient temperature at spray boundary. However, the higher heat capacity caused by higher ambient pressure seems to mitigate the decrease of ambient temperature and increase evaporation rate and fuel-air mixing rate [31]. Therefore, the spray characteristics and mixture formation process may affect this kind of pressure history, which will be discussed later. 

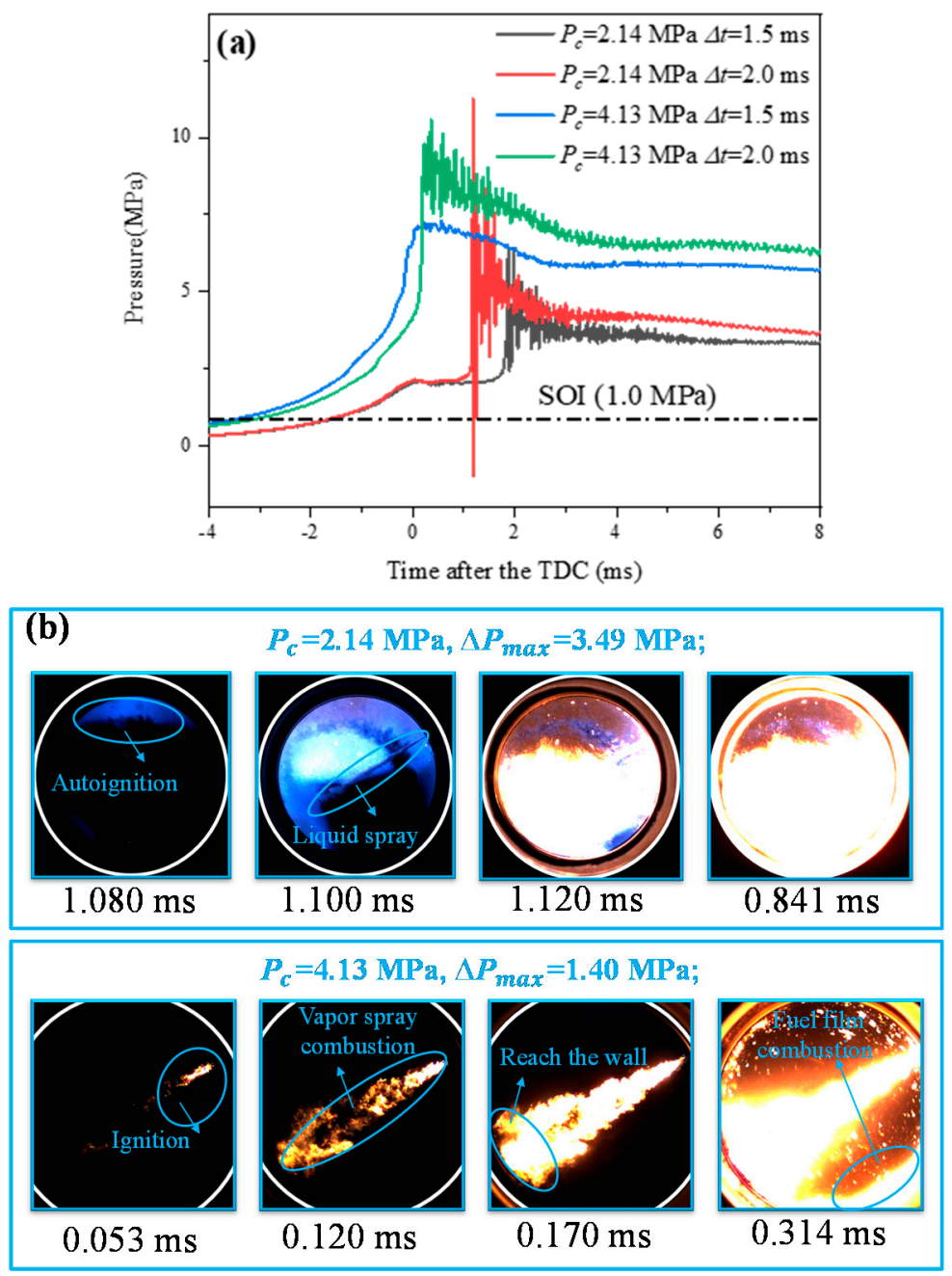

Figure 9. In-cylinder pressure and selected images of combustion evolution at FIP $=40 \mathrm{MPa}$ : (a) In-cylinder pressure at FIP $=40 \mathrm{MPa}$; (b) Selected images of combustion evolution under the conditions of FIP $=40 \mathrm{MPa}$ and $\Delta t=2.0 \mathrm{~ms}$.

The visualization images displayed in Figure $9 \mathrm{~b}$ further show the combustion revolution under two ambient pressure conditions. As seen from the first row, for $P_{c}=2.14 \mathrm{MPa}$, auto-ignition kernel with blue luminosity firstly occurs at the upper corner of the combustion chamber when the time comes to $t=1.080 \mathrm{~ms}$ after the TDC. At $P_{c}=4.13 \mathrm{MPa}$, a small area of yellow flame appears within the beam of spray at earlier time. This result indicates that the longer ignition delay is a kind of signal that more liquid spray may impinge on the wall under low ambient pressure conditions. From the second column of the images, liquid spray is observed with the help of the higher natural luminescence intensity. This indicates that liquid spray is continuously impinging against the wall even after auto-ignition under the conditions of $P_{c}=2.14 \mathrm{MPa}$. However, the spray droplets have been evaporated completely before impinging on the wall when ambient pressure exceeds $4 \mathrm{MPa}$ [32]. A more combustible mixture is formed locally, and the bright yellow flame is observed near the spray centerline. Then, the flame reaches the wall and ignites the attached fuel film. From the above phenomenon observed under critical conditions, higher ambient pressure weakens liquid spray impingement by accelerating spray evaporation and thereby decreases ignition delay, which shifts diesel knock into normal combustion.

\subsubsection{Knocking Conditions}

As shown in Figures 7 and 8, diesel knock is inevitable when FIP exceeds $40 \mathrm{MPa}$ under two scenarios. However, knock intensity under low ambient pressure conditions is still higher. Figure 10 
shows combustion evolution at FIP $=50 \mathrm{MPa}$ and $\Delta t=2.0 \mathrm{~ms}$, while the combustion evolution at $\mathrm{FIP}=60 \mathrm{MPa}$ and $\Delta t=2.0 \mathrm{~ms}$ can be seen in Supplementary Materials. Near-wall autoignition is both observed under two scenarios. However, lots of spray droplets lack sufficient time to form mixture due to higher ambient pressure, which indicates that diffusion flame is prior to the autoignition onset. Then, the induced autoignition reaction waves propagate toward the bottom of the combustion chamber with a similar propagation path. Compared with high ambient pressure condition, the reaction wave at $P_{c}=2.14 \mathrm{MPa}$ emits much brighter chemiluminescence with a higher propagation speed. Subsequently, this reaction wave reaches the chamber wall, resulting in stronger pressure oscillation.
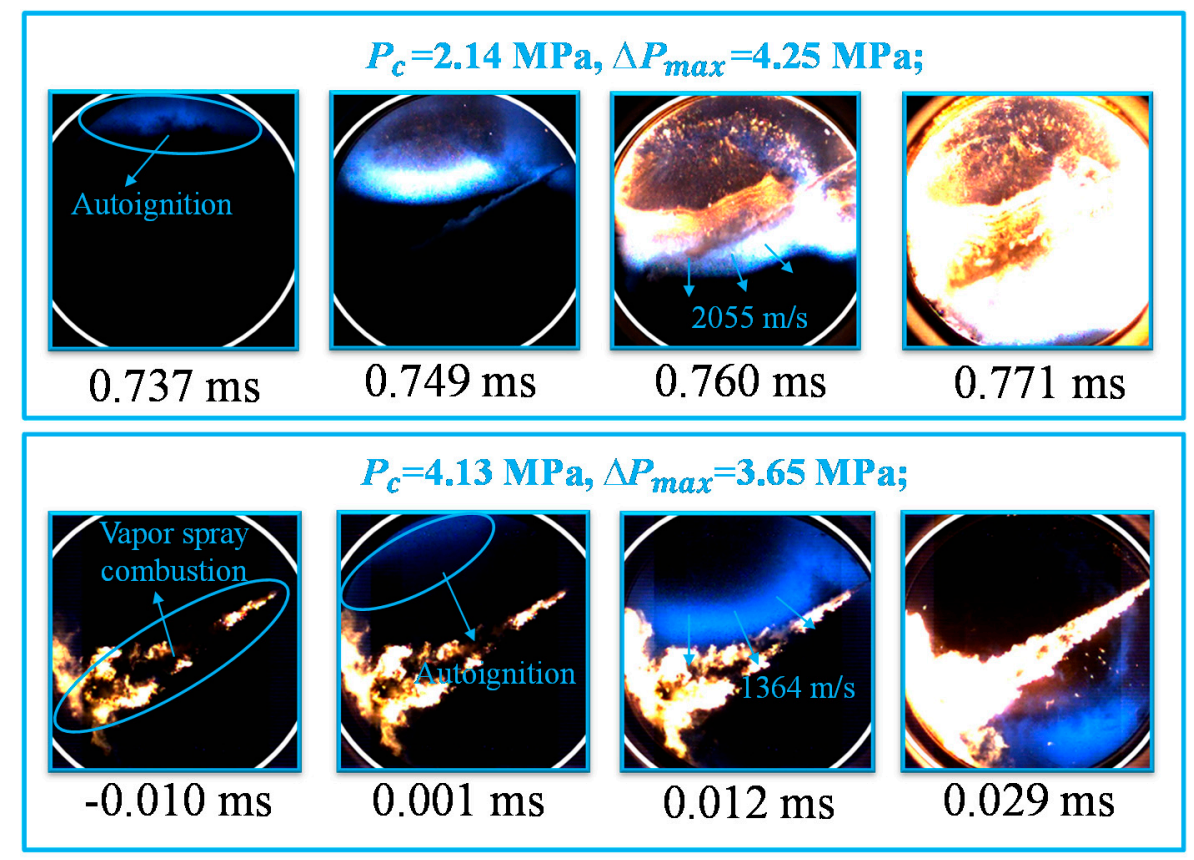

Figure 10. Selected images of combustion evolution under the conditions of FIP $=50 \mathrm{MPa}$ and $\Delta t=2.0 \mathrm{~ms}$.

\subsection{Analysis of Pressure Oscillation}

The effects of fuel injection pressure and ambient pressure on diesel knock have been discussed; however, the underlying reasons for the formation of pressure oscillation are not clarified. Figure 11 presents the pressure trace, combustion images and filtered pressure rise rate (PRR) of a typical diesel knock experiment at FIP $=50 \mathrm{MPa}, P_{c}=2.14 \mathrm{MPa}$ and $\Delta t=2.0 \mathrm{~ms}$. The injector starts to inject fuel into the chamber at $t=1.09 \mathrm{~ms}$ before the TDC. The in-cylinder pressure begins to rise and the PRR reaches the first peak at $t=0.45 \mathrm{~ms}$ after the TDC, or the time of Figure 11a. This peak is considered to be related to the first stage ignition of the fuel-air mixture, since diesel fuel has a two-stage ignition characteristic [25]. However, the first-stage ignition is difficult to be recorded by the camera due to its low natural luminescence intensity. Generally, the ignition delay time is defined as the time between the start of injection and the start of combustion (SOC) [33]. And the ignition delay period is about $1.54 \mathrm{~ms}$ due to the early injection and spray impingement, which is relatively long for conventional diesel engine. A large proportion of fuel-air mixture is prepared within the long ignition delay, which enhances the premixed combustion. Subsequently, a second PRR peak occurs at $t=0.74 \mathrm{~ms}$, in Figure 11b. At this moment, a brighter autoignition kernel appears upper corner of the combustion chamber, which indicates second-stage ignition of mixture. Then, an induced reaction-front propagates into the other unburnt region with brighter chemiluminescence. Just $0.02 \mathrm{~ms}$ later, i.e. at the time of Figure 11c, the speed of reaction front is approximately $2055 \mathrm{~m} / \mathrm{s}$. Such a speed is higher than C-J detonation speed, which indicates that the second-stage autoignition has developed into a detonation wave [34]. Subsequently, this reaction-front reaches the chamber wall, resulting in a pressure peak in 
the combustion chamber. When the propagating reaction front collides at the cylinder wall, there is forming an incandescent zone, as shown in Figure 11d. The reaction-front propagates back and forth in the combustion chamber, which is consistent with the recorded pressure oscillation depicted in pressure traces.

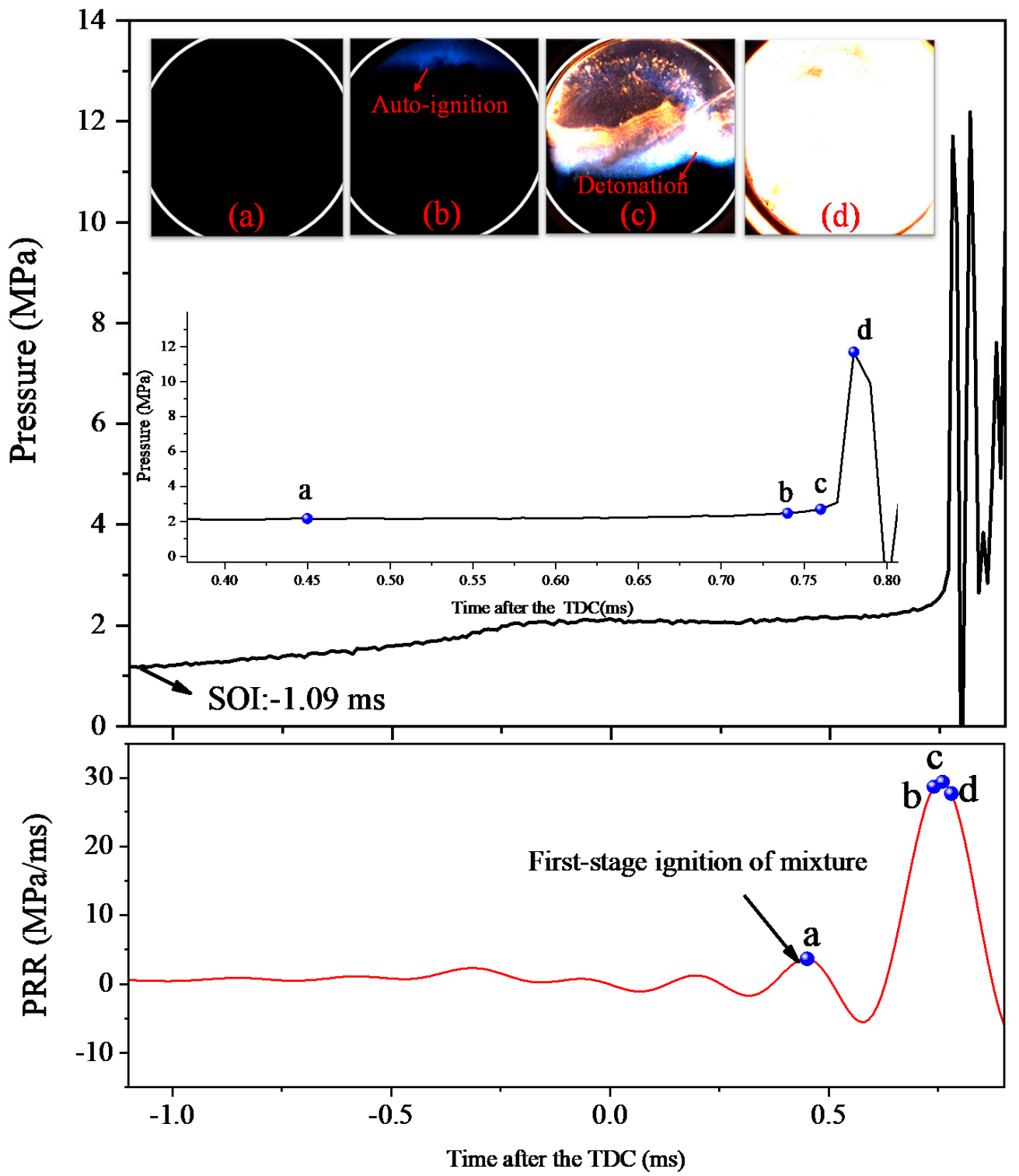

Figure 11. Pressure trace with synchronous images under the conditions of $P_{c}=2.14 \mathrm{MPa}, \mathrm{FIP}=50 \mathrm{MPa}$, $\Delta t=2.0 \mathrm{~ms}$.

It is well known that the pressure oscillation induced by diesel knock is closely related to chamber resonance phenomena. Using fast Fourier transform analysis for pressure traces, Figure 12 shows the unfiltered pressure spectrum to further clarify frequency characteristics of pressure oscillation. It can be seen that there are three strong peaks, located at $7.2 \mathrm{kHz}, 14.1 \mathrm{kHz}$ and $16.9 \mathrm{kHz}$, and several weaker peaks at other frequencies. The $7.2 \mathrm{kHz}$ frequency is the first-order circumferential vibration mode, and the second circumferential vibration mode is at approximately $14.1 \mathrm{kHz}$. In addition, it should be noted that the oscillation peak for the first-order circumferential vibration mode is highest for this condition which always produces heavy knock [35]. The pressure oscillation frequency depends on the propagation speed of pressure waves [36], which indicates that the formation of pressure oscillation is 
mainly due to the propagation of the detonation wave stemming from the second-stage autoignition, and the pressure oscillation fluctuates back and forth in the confined combustion chamber.

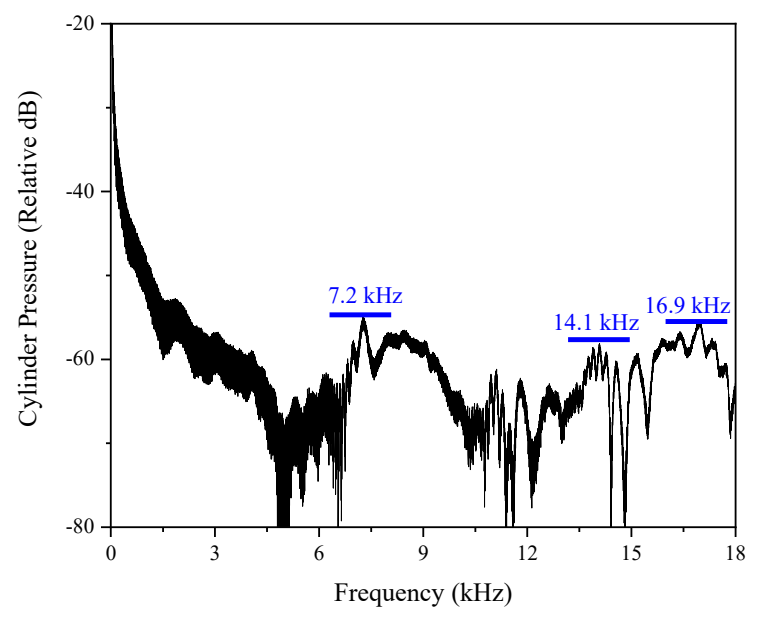

Figure 12. FFT analysis of in-cylinder pressure at $P_{c}=2.14 \mathrm{MPa}, \mathrm{FIP}=50 \mathrm{MPa}, \Delta t=2.0 \mathrm{~ms}$.

\section{Conclusions}

In this study, diesel knock with destructive pressure oscillation for high altitude heavy-duty engines was reproduced in a high-strength optical rapid compression machine. High-speed direct photography and simultaneous pressure acquisition were synchronically performed to comparatively investigate the effect of fuel injection pressure and ambient pressure. Meanwhile, typical visualization images and the pressure traces were analysed to understand the underlying reasons for the formation of pressure oscillation.

For the given ambient temperatures and pressures, diesel knock becomes prevalent with the increase of fuel injection pressure. Possible reasons are that high fuel injection pressure can increase injected fuel mass and accelerates the atomization process, which elevates the burning rate and shortens the combustion duration.

Higher ambient pressure reduces the tendency to diesel knock under critical conditions. For the given injection pressure satisfying knocking combustion, knock intensity is decreased as ambient pressure is increased. This is mainly because higher ambient pressures weaken liquid spray impingement by accelerating spray evaporation and thereby decrease ignition delay, which suppresses the autoignition occurrence and decreases the propagation speed of the reaction-front.

Further analysis on visualization images shows that the diesel spray-wall impingement leads to longer ignition delay time, by which diesel knock is induced. The autoignition of mixture exhibited a two-stage ignition characteristic, and the supersonic reaction-front induced by second-stage autoignition propagates back and forth in the combustion chamber, which results in high-frequency pressure oscillation. In addition, the dominant oscillation frequencies are obtained through the FFT analysis, located at 7.2, 14.1 and $16.9 \mathrm{kHz}$.

Supplementary Materials: The following are available online at http://www.mdpi.com/1996-1073/13/12/3080/s1, Figure S1: Selected images of combustion evolution under the conditions of FIP $=60 \mathrm{MPa}$ and $\Delta t=2.0 \mathrm{~ms}$.

Author Contributions: Conceptualization, X.W., H.W., J.P. and M.P.; methodology, X.W., J.P., Z.H. and Z.Z.; software, X.W.; validation, H.W., Z.H.; formal analysis, X.W., J.P. and Z.Z.; investigation, X.W., J.P., Z.H. and M.P.; resources, H.W.; data curation, X.W. and Z.H.; writing-original draft preparation, X.W.; writing-review, H.W. and J.P.; visualization, Z.Z.; supervision, H.W., J.P. and M.P.; project administration, X.W.; funding acquisition, H.W. All authors have read and agreed to the published version of the manuscript.

Funding: This research was funded by National Natural Science Foundation of China (Grant No. 51706152, 51825603) and Tianjin Natural Science Foundation (Grant No. 18JCQNJC07500).

Conflicts of Interest: The authors declare no conflict of interest. 


\section{References}

1. Kan, Z.; Hu, Z.; Lou, D.; Tan, P.; Cao, Z.; Yang, Z. Effects of altitude on combustion and ignition characteristics of speed-up period during cold start in a diesel engine. Energy 2018, 150, 164-175. [CrossRef]

2. Wang, X.; Ge, Y.; Yu, L.; Feng, X. Comparison of combustion characteristics and brake thermal efficiency of a heavy-duty diesel engine fueled with diesel and biodiesel at high altitude. Fuel 2013, 107, 852-858. [CrossRef]

3. Shen, L.; Shen, Y.; Yan, W.; Xu, J. Combustion process of diesel engines at regions with different altitude. SAE Tech. Pap. 1995. [CrossRef]

4. Meininger, R.D.; Kweon, C.-B.M.; Szedlmayer, M.T.; Dang, K.Q.; Jackson, N.B.; Lindsey, C.A.; Gibson, J.A.; Armstrong, R.H. Armstrong, Knock criteria for aviation diesel engines. Int. J. Engine Res. 2016, 18, 752-762. [CrossRef]

5. Heywood, J. Internal Combustion Engine Fundamentals; McGraw-Hill Education: New York, NY, USA, 1988.

6. Syrimis, M.; Assanis, D. Knocking cylinder pressure data characteristics in a spark-ignition engine. J. Eng. Gas Turbines Power 2003, 125, 494-499. [CrossRef]

7. Ren, Y.; Randall, R.; Milton, B. Influence of the resonant frequency on the control of knock in diesel engines. Proc. Inst. Mech. Eng. D 1999, 213, 127-133. [CrossRef]

8. Hickling, R.; Feldmaier, D.; Sung, S. Knock-induced cavity resonances in open chamber diesel engines. Acoust. Soc. Am. 1979, 65, 1474-1479. [CrossRef]

9. Rusly, A.; Kook, S.; Hawkes, E.; Zhang, R. High-speed imaging of soot luminosity and spectral analysis of in-cylinder pressure trace during diesel knock. SAE Tech. Pap. 2014. [CrossRef]

10. Zhao, M.; Kaiser, S. Optical Diagnostics for Knock in Compression-Ignition Engines via High-Speed Imaging. SAE Int. J. Engines 2018, 11, 903-918. [CrossRef]

11. Pan, J.; Hu, Z.; Wei, H.; Pan, M.; Liang, X.; Shu, G.; Zhou, L. Understanding strong knocking mechanism through high-strength optical rapid compression machines. Combust. Flame 2019, 202, 1-15. [CrossRef]

12. Qi, Y.; Wang, Z.; Wang, J.; He, X. Effects of thermodynamic conditions on the end gas combustion mode associated with engine knock. Combust. Flame 2015, 162, 4119-4128. [CrossRef]

13. Wang, Z.; Qi, Y.; He, X.; Wang, J.; Shuai, S.; Law, C.K. Analysis of pre-ignition to super-knock: Hotspot-induced deflagration to detonation. Fuel 2015, 144, 222-227. [CrossRef]

14. Kawahara, N.; Tomita, E.; Sakata, Y. Auto-ignited kernels during knocking combustion in a spark-ignition engine. Proc. Combust. Inst. 2007, 31, 2999-3006. [CrossRef]

15. Agarwal, A.K.; Dhar, A.; Gupta, J.G.; Kim, K.; Choi, W.I.; Lee, C.S.; Park, S. Effect of fuel injection pressure and injection timing of Karanja biodiesel blends on fuel spray, engine performance, emissions and combustion characteristics. Energy Convers. Manag. 2015, 91, 302-314. [CrossRef]

16. Liu, F.; Yang, Z.; Li, Y.; Wu, H. Experimental study on the combustion characteristics of impinging diesel spray at low temperature environment. Appl. Therm. Eng. 2019, 148, 1233-1245. [CrossRef]

17. Agarwal, A.K.; Dhar, A.; Gupta, J.G.; Kim, W.I.; Lee, C.S.; Park, S. Effect of fuel injection pressure and injection timing on spray characteristics and particulate size-number distribution in a biodiesel fuelled common rail direct injection diesel engine. Appl. Energy 2014, 130, 212-221. [CrossRef]

18. Martin, G.C.; Mueller, C.J.; Milam, D.M.; Radovanovic, M.S.; Gehrke, C.R. Early direct-injection, low-temperature combustion of diesel fuel in an optical engine utilizing a 15-hole, dual-row, narrow-included-angle nozzle. SAE Int. J. Engines 2009, 1, 1057-1082. [CrossRef]

19. Du, W.; Zhang, Q.; Zhang, Z.; Lou, J.; Bao, W. Effects of injection pressure on ignition and combustion characteristics of impinging diesel spray. Appl. Energy 2018, 226, 1163-1168. [CrossRef]

20. Khalid, A. Effect of ambient temperature and oxygen concentration on ignition and combustion process of diesel spray. Asian J. Sci. Res. 2013, 6, 434-444. [CrossRef]

21. Jaat, M.; Khalid, A.; Sapit, A.; Basharie, S.M.; Andsaler, A.R.; Ramsy, H. Effects of temperature and ambient pressure on spray characteristics of biodiesel combustion. Appl. Mech. Mater. 2015, 773, 501-505. [CrossRef]

22. Jain, A.; Singh, A.P.; Agarwal, A.K. Effect of fuel injection parameters on combustion stability and emissions of a mineral diesel fueled partially premixed charge compression ignition (PCCI) engine. Appl. Energy 2017, 190, 658-669. [CrossRef] 
23. Kyrtatos, P.; Hoyer, K.; Obrecht, P.; Boulouchos, K. Apparent effects of in-cylinder pressure oscillations and cycle-to-cycle variability on heat release rate and soot concentration under long ignition delay conditions in diesel engines. Int. J. Engine Res. 2014, 15, 325-337. [CrossRef]

24. Mittal, G.; Bhari, A. A rapid compression machine with crevice containment. Combust. Flame 2013, 160, 2975-2981. [CrossRef]

25. Yu, L.; Mao, Y.; Qiu, Y.; Wang, S.; Li, H.; Tao, W.; Qian, Y.; Lu, X. Experimental and modeling study of the autoignition characteristics of commercial diesel under engine-relevant conditions. Proc. Combust. Inst. 2019, 37, 4805-4812. [CrossRef]

26. Wang, X.; Ge, Y.; Yu, L.; Feng, X. Effects of altitude on the thermal efficiency of a heavy-duty diesel engine. Energy 2013, 59, 543-548. [CrossRef]

27. Weber, B.W.; Sung, C.-J.; Renfro, M.W. On the uncertainty of temperature estimation in a rapid compression machine. Combust. Flame 2015, 162, 2518-2528. [CrossRef]

28. Wang, Z.; Liu, H.; Song, T.; Qi, Y.; He, X.; Shuai, S.; Wang, J. Relationship between super-knock and pre-ignition. Int. J. Engine Res. 2015, 16, 166-180. [CrossRef]

29. Shi, Z.; Lee, C.-F.; Wu, H.; Li, H.; Wu, Y.; Zhang, L.; Bo, Y.; Liu, F. Effect of injection pressure on the impinging spray and ignition characteristics of the heavy-duty diesel engine under low-temperature conditions. Appl. Energy 2020, 262, 114552. [CrossRef]

30. Mohammadi, A.; Kidoguchi, Y.; Miwa, K. Effect of injection parameters and wall-impingement on atomization and gas entrainment processes in diesel sprays. SAE 2002, 1, 1070-1079.

31. Khalid, A.; Yatsufusa, T.; Miyamoto, T.; Kawakami, J.; Kidoguchi, Y. Analysis of relation between mixture formation during ignition delay period and burning process in diesel combustion. SAE Tech. Pap. 2009. Available online: https://www.sae.org/publications/technical-papers/content/2009-32-0018/ (accessed on 13 June 2020).

32. Chen, B.; Feng, L.; Wang, Y.; Ma, T.; Liu, H.; Geng, C.; Yao, M. Spray and flame characteristics of wall-impinging diesel fuel spray at different wall temperatures and ambient pressures in a constant volume combustion vessel. Fuel 2019, 235, 416-425. [CrossRef]

33. Dhole, A.; Yarasu, R.; Lata, D. Investigations on the combustion duration and ignition delay period of a dual fuel diesel engine with hydrogen and producer gas as secondary fuels. Appl. Therm. Eng. 2016, 107, 524-532. [CrossRef]

34. Gu, X.J.; Emerson, D.R.; Bradley, D. Modes of reaction front propagation from hot spots. Combust. Flame 2003, 133, 63-74. [CrossRef]

35. Brunt, M.F.J.; Pond, C.R.; Biundo, J. Gasoline Engine Knock Analysis using Cylinder Pressure Data. SAE Tech. Pap. 1998. [CrossRef]

36. Pan, J.; Shu, G.; Wei, H. Research on in-cylinder pressure oscillation characteristic during knocking combustion in spark-ignition engine. Fuel 2014, 120, 150-157. [CrossRef] 